\title{
La repercusión económico-contable de la baja del socio en la sociedad cooperativa: la incidencia de la NIC $32^{1}$
}

The economic-accounting impact of the members withdrawal in cooperative society: the impact of IAS 32

\author{
Juana Isabel Genovart Balaguer² \\ Emilio Mauleón Méndez ${ }^{3}$ \\ Universidad de las Islas Baleares (España)
}

Sumario: I. Introducción. II. La armonización contable internacional y su incidencia en la regulación contable de las cooperativas en España. 2.1 El proceso de armonización contable internacional. 2.2 La reforma de la contabilidad en España para adaptarla al proceso de armonización contable. 2.3 La incidencia de la reforma contable en las sociedades cooperativas. III. Antecedentes históricos al actual tratamiento del capital contable cooperativo. IV. Concepción contable del capital cooperativo, según normas internacionales de contabilidad. V. Concepción contable del capital cooperativo, según la normativa española. VI. Conclusiones. VII. Bibliografía.

Summary: I. Introduction. II. International accounting harmonization and its impact on the accounting regulation of cooperatives in Spain. 2.1 The process of international accounting harmonization. 2.2 The reform of the accounting in Spain to adapt it to the process of accounting harmonization. 2.3 The impact of accounting reform on cooperatives. III. Historical background to the current treatment of cooperative stock capital. IV. Accounting concept of cooperative stock capital, according to international accounting standards. V. Accounting concept of cooperative stock capital, according to Spanish regulation. VI. Conclusions. VII. Bibliography.

1 Trabajo de investigación realizado en el marco del Proyecto de Investigación DER2013-48864-C2-1-P, con el título «Integración cooperativa y reestructuraciones socialmente responsables. Mecanismos de creación de empleo e incremento de la productividad empresarial», financiado por el Ministerio de Economía y Competitividad del Gobierno de España.

2 Correo electrónico: juanabel.genovart@uib.es

3 Correo electrónico: emilio.mauleon@uib.es 
Resumen: En aras al principio de adhesión voluntaria y abierta, las cooperativas presentan singularidades en torno a la figura del capital social, que las diferencia de otras entidades mercantiles. Dichas peculiaridades comportan un tratamiento contable especial del capital cooperativo. Las normas internacionales de contabilidad prevén la calificación contable del capital cooperativo como pasivo financiero o como fondo propio, según la regulación legal y/o estatutaria del derecho de baja del socio. Este planteamiento se ha traspuesto al derecho contable de la Unión Europea y de España, afectando a un buen número de cooperativas europeas, incidiendo en su imagen financiera. En este trabajo tratamos las peculiaridades contables que emanan de la posibilidad de la baja del socio en el marco de la normativa contable internacional, nacional y los últimos posicionamientos de organismos reguladores.

Palabras clave: entidades de participación, cooperativas, contabilidad cooperativas, capital social, baja del socio.

Abstract: The share capital of cooperatives has different characteristics to the share capital of other commercial entities. This is due to the principle of voluntary and open membership. These peculiarities make the cooperative capital have a special accounting treatment. According to international accounting standards, cooperative capital can be considered as a financial liability or a capital resource, depending on the legal or statutory regulation of the partner's right of withdrawal. This approach has also been applied to the accounting law of the European Union and Spain, affecting many European cooperatives, affecting their financial image. In this paper, we analyze the accounting peculiarities that take place when a partner leaves the cooperative, according to the international accounting regulations, national accounting regulations and the last positions of the regulatory organisms

Keywords: social entity, cooperatives, cooperative accounting, social capital, partner's withdrawal 


\section{Introducción}

La causa principal por la que se considera la variabilidad del capital social cooperativo, radica en el principio de adhesión voluntaria y abierta establecido por la Alianza Cooperativa Internacional ${ }^{4}$. Las cooperativas de acuerdo a su Ley estatal son «sociedades constituidas por personas que se asocian, en régimen de libre adhesión y baja voluntaria,...», es decir, cualquier persona, cumpliendo una serie de requisitos especiales, legales y estatutarios, puede entrar a ser socio de una cooperativa (libre adhesión), pero también puede decidir, de manera voluntaria y en cualquier momento, dejar de ser cooperativista y causar baja en la sociedad (baja voluntaria), estando obligada la cooperativa, siempre que por ley así se indique, a la liquidación de sus aportaciones iniciales, según el balance existente a la fecha de cierre de ejercicio.

En la mayoría de los casos, ese principio de libre adhesión no se conceptualiza como un derecho de adhesión. Es decir, la cooperativa no tiene la obligación de aceptar a cualquier persona que quiera formar parte de ella, sin más. En general, serán los estatutos los que determinarán los requisitos que debe cumplir una persona, para poder ser socio de una cooperativa. Entre dichos requisitos puede incluirse la obligación de ser persona física o jurídica; el perfil laboral y/o profesional; los requisitos geográficos; los bienes que debe aportar o las cuotas de ingreso que debe satisfacer. Será el Consejo Rector u órgano de gobierno procedente, el que determinará motivadamente, su inclusión o rechazo a poder ser socio de la cooperativa.

En este sentido, el criterio de libre adhesión hace referencia a que la solicitud de entrada, que no el derecho de entrada, puede emanar directamente de una tercera persona, externa a la entidad, pero será la propia cooperativa la que decidirá o no su inclusión. Por contra a este criterio, en las sociedades de capital, la solicitud de entrada de nuevos socios la inicia la propia sociedad cuando se trata de una ampliación de capital o bien los antiguos socios, si se realiza una compra-venta de acciones o de participaciones. En este sentido puede destacarse como diferencia respecto de las entidades capitalistas, que en las cooperativas, la entrada de un nuevo socio no lleva siempre pareja la salida de otro o bien la solicitud, por parte de la empresa, de realizar una ampliación de capital.

${ }^{4}$ Como señalan Vargas Vasserot, Gadea Soler y Sacristán Bergia, 2015: 35, los principios son mandamientos que deben ser seguidos por las cooperativas, si bien no es suficiente preguntarnos si una cooperativa los sigue al pie de la letra, es igualmente importante saber si sigue su espíritu. 
Por su parte, en las entidades capitalistas, la salida voluntaria de los socios requiere la previa venta de sus acciones o participaciones a alguien, con la finalidad de mantener así inalterada la cifra de capital social. Esta afirmación tiene sus excepciones (arts. 346 y 347 LSC), ya que, en determinadas circunstancias, tasadas por Ley, un socio puede causar baja en una sociedad anónima o de responsabilidad limitada, sin vender sus acciones o participaciones. En las cooperativas, sin embargo, el mecanismo por el que un socio se da de baja de la sociedad es más sencillo, ya que en principio, si un socio quiere separarse de la entidad, puede hacerlo simplemente cumpliendo unos determinados requisitos formales y siguiendo el procedimiento establecido en los estatutos, calificándose la baja como voluntaria o por justa causa.

Cuando un socio cause baja en la cooperativa la entidad está obligada a la liquidación de sus aportaciones al capital social ${ }^{5}$, con la consecuente reducción de capital que ello provoca. El socio no tiene derecho a la devolución de una cantidad idéntica al nominal que aportó en su día a la entidad, sino que se le reintegrarán sus aportaciones sociales al valor de liquidación que tengan en ese momento. Para calcular dicho valor de liquidación, se detraerá de la cantidad que el socio aportó en su día, tanto las pérdidas imputadas e imputables al socio, reflejadas en el balance de cierre del ejercicio en el que se produzca la baja como, en el caso de baja no justificada, una cantidad en concepto de indemnización, que se imputará a reservas irrepartibles. El importe máximo de dicha indemnización variará dependiendo de la legislación autonómica aplicable.

Sin embargo, en la actualidad se permite la existencia de aportaciones de socios al capital, cuyo reembolso, en caso de baja, pueda ser rehusado incondicionalmente por el Consejo Rector. Lo anterior tuvo lugar a raíz de una modificación de la Ley de cooperativas estatal (art. 45.1)6

${ }^{5}$ El art. 16 Ley 27/1999 estatal de Cooperativas lo enumera como uno de los derechos de los socios. También enuncian el derecho al reembolso de las aportaciones por baja, las legislaciones autonómicas, aunque algunas de ellas dejan la puerta entreabierta al añadir la coletilla «en su caso», o bien «si procede». En particular, regulan este derecho la LCMU (art. 71); la LCB (art. 20 y art. 76); la LCC (art. 23) aunque especifica que sin perjuicio de lo que dispongan los estatutos sociales en relación con las aportaciones cuyo reembolso pueda ser rehusado incondicionalmente por el Consejo Rector; la LCAN (art. 60), aunque en el mismo sentido anterior; la LCV (art. 25); la LCAR (art. 19); la LCE (art. 23); la LCN (art. 25), aunque habla de compensaciones económicas; la LCLR (art. 24); la LCCM (art. 35 y art. 82), en este caso se habla de que los estatutos regularán las condiciones en que proceda o no proceda el ejercicio del derecho al reembolso; la LCCL (art. 22 y 66); la LCM (art. 23 y 55); la LCG (art. 22 y 64); la LCAS (art. 27 y art. 88) aunque establece la posibilidad de que el Consejo Rector rehúse el reembolso; y la LCEX (art. 23 y 57).

6 Establecida en virtud de la disposición adicional cuarta de la Ley 16/2007, de 4 de julio, de reforma y adaptación de la legislación mercantil en materia contable para su ar- 
que tuvo su precedente en la modificación del Reglamento de cooperativas de crédito, en 2005; en la Ley autonómica de cooperativas del País Vasco y en la Ley foral de cooperativas de Navarra, en 2006.

En la actualidad existen pues dos tipos de capital social cooperativo, el reintegrable puro y simple y el reintegrable condicionado. La totalidad de las leyes cooperativas autonómicas, han incluido esta distinción entre capital con derecho a reembolso y con reembolso que pueda rehusar el Consejo Rector.

Hasta la entrada en vigor de la Ley 16/2007 de reforma mercantil, todos los socios, al causar baja en la cooperativa, podían exigir la restitución de sus aportaciones iniciales en el importe correspondiente a su valor de liquidación, calculado según el balance de cierre del ejercicio. La inclusión posterior de aportaciones con reembolso condicionado a la decisión del Consejo Rector se relaciona con la nueva distinción contable entre pasivos financieros y patrimonio neto, en orden a lo estipulado por la Norma Internacional de Contabilidad número 32 (en adelante NIC 32), la interpretación número 2 del Comité de Interpretaciones de Normas Internacionales de Información Financiera (CINIFF 2) del International Financial Reporting Standards Committee (IFRIC) y la propia reforma contable española.

Este nuevo planteamiento pretendía evitar que la totalidad del capital social cooperativo fuera calificado contablemente como un recurso ajeno atendiendo a su carácter reintegrable, como un pasivo financiero, lo que podría conllevar a una descapitalización contable de la mayoría de sociedades cooperativas. Sin embargo, esta problemática no está exenta de polémica y ha sido objeto de discusión por parte de los organismos reguladores contables, tanto a nivel nacional como internacional.

La modificación operada en la Ley de cooperativas estatal (art. 45.1 in fine), incluye también una opción que permite, cuando en un ejercicio económico el importe de la devolución de las aportaciones correspondientes al capital reintegrable supere un determinado porcentaje de capital social, fijado en estatutos, el establecimiento de una opción estatutaria a que los nuevos reembolsos estén condicionados al acuerdo favorable del Consejo Rector.

Estos cambios normativos aunaron un poco más el concepto de capital social cooperativo al del capital social de las entidades capitalistas, al limitarse significativamente su carácter variable, dotándolo, por tanto, de mayor estabilidad. Sin embargo, a simple vista, pudiera pa-

monización internacional con base en la normativa de la Unión Europea, que entró en vigor el 1 de enero de 2008. 
recer que contradice uno de los principios gestores del movimiento cooperativo, el de puertas abiertas a la libre entrada y salida de socios. Consideramos que esta modificación normativa no rebate tal principio, por cuanto que no limita la salida de socios, únicamente limita el derecho al reembolso de sus aportaciones. Los socios pueden salir libremente de la entidad, aunque no tengan el derecho a la restitución de lo aportado, calculado de acuerdo a su valor de liquidación. Según el principio de puertas abiertas, las cooperativas deben estar abiertas a cualquier persona interesada en formar parte de ellas, siempre que dicha persona cumpla con determinados requisitos y que puedan, en cualquier momento, abandonar la cooperativa, tengan o no el derecho de reembolso de sus aportaciones al causar baja7.

El objetivo de este trabajo, es el estudio de las consecuencias en el plano contable de la baja del socio en la cooperativa, a partir de la NIC 32 y su incidencia en la normativa contable española.

En los apartados siguientes analizaremos la controvertida calificación contable del capital social cooperativo, tanto en base a las NIC como sobre la norma doméstica española, ofreciendo un análisis crítico. En la consecución de nuestro objetivo, se ha seguido la siguiente metodología: en primer lugar se ha realizado un análisis del estado de la cuestión, repasando la literatura existente al respecto, y tras lo anterior, sobre la base de la metodología lógico-deductiva, se ha procedido a un análisis crítico de los textos legales y doctrinales sobre la calificación contable del capital social cooperativo.

Antes de profundizar en la repercusión económico-contable que supone la baja del socio cooperativo, describiremos brevemente el proceso de armonización de la normativa contable a nivel internacional que, en nuestro país, culminó con una profunda reforma de nuestro Derecho contable, junto con la aprobación de dos nuevos Planes Generales de contabilidad y a nivel cooperativo, la aprobación de unas nuevas normas sobre aspectos contables de las sociedades cooperativas.

\section{La armonización contable internacional y su incidencia en la regulación contable de las cooperativas en España}

\subsection{El proceso de armonización contable internacional}

Desde finales del siglo $x x$ hemos venido experimentando un período de cambios contables importantes. Fruto de la globalización eco-

7 En la misma línea opina Vargas Vasserot 2011: 8-9. 
nómica y en aras a una mejor comparabilidad y fiabilidad de la información contable entre las empresas de diferentes países, se gestó un movimiento de cambio consistente en la armonización y homogeneización del Derecho contable, no sólo a nivel de comunidad europea, sino a nivel del conjunto del mercado mundial.

En 1995, se dio un primer paso en dicha armonización contable internacional mediante la publicación de la Comunicación de la Comisión Europea que llevaba por título: "Armonización Contable: una nueva estrategia de cara a la armonización internacional». Sin embargo, no fue hasta el año 2002 cuando se integraron las Normas Internacionales de Información Financiera (denominadas NIC y posteriormente NIIF) a nivel europeo. Mediante el Reglamento (CE) n. ${ }^{\circ}$ 1606/2002 del Parlamento Europeo y del Consejo (DOCE n. ${ }^{\circ} 243$ ), relativo a la aplicación de las normas internacionales de contabilidad, se recogió el compromiso, por parte de la Unión Europea, de aplicar un conjunto único de normas internacionales de contabilidad.

Las NIIF son normas contables individuales elaboradas por el Internacional Accounting Standard Board (denominado por las siglas IASB), organismo privado de carácter internacional con gran prestigio en el ámbito contable, cuyo objetivo consiste en formular un grupo único de normas mundiales de contabilidad. Los estados miembros deben aplicar las NIIF junto con su Marco Conceptual ${ }^{8}$, que establece los principios generales que deben regir la preparación y presentación de estados financieros; y las Interpretaciones sobre las normas individuales que emite el IFRIC, a fin de facilitar la aplicación de las normas.

Se estableció la aplicación obligatoria de las NIIF, para los ejercicios que comenzaran a partir del 1 de enero de 2005, en la formulación de las cuentas anuales consolidadas de las sociedades cuyos valores cotizaran en algún mercado regulado de cualquier Estado miembro de la Unión Europea. Dicha fecha se amplió a 1 de enero de 2007 para los grupos, que no fueran entidades de crédito, que sólo hubieran emitido valores de renta fija admitidos a cotización. Por último, se previó en el reglamento, una extensión de la aplicación de las NIIF a las cuentas anuales de sociedades que no cotizaran, aunque a opción de cada Estado Miembro.

8 Framework for the Preparation and Presentation of Financial Statements. En julio de 1989 el IASC publicó su propuesta de marco conceptual, siendo adoptado por el IASB en abril de 2001. 


\subsection{La reforma de la contabilidad en España para adaptarla al proceso de armonización contable}

En el año 2002, se publicó en España el denominado «Libro Blanco de la Contabilidad». Se trataba de un informe elaborado por una comisión de expertos contables, constituida a instancias del Ministerio de Economía, en el que se recomendaba la aplicación de las NIIF a todas las empresas, cotizadas o no, en la elaboración de sus cuentas anuales consolidadas. Sin embargo, permitía que las cuentas anuales individuales de cualquier sociedad siguieran elaborándose utilizando exclusivamente normativa contable española. Recomendaban, por otra parte, la adaptación de dicha normativa a fin de compatibilizar sus criterios con los de las NIC y su Marco Conceptual, para conseguir una adecuada homogeneidad y comparabilidad de la información financiera, a nivel internacional.

En esta línea, la profunda reforma del Derecho contable español, fue operada por la Ley 16/2007 junto con la aprobación de los dos nuevos Planes Generales Contables españoles. En la actualidad, el Plan General de Contabilidad (PGC en adelante), aprobado por Real Decreto 1514/2007, es de aplicación obligatoria para todas las empresas, sin perjuicio de aquéllas que puedan aplicar el Plan General de Contabilidad de Pequeñas y Medianas Empresas, aprobado por Real Decreto $1515 / 2007$.

\subsection{La incidencia de la reforma contable en las sociedades cooperativas}

El artículo 61.1 de la Ley 27/1999 de cooperativas estatal establece que «las cooperativas deberán llevar una contabilidad ordenada y adecuada a su actividad con arreglo a lo establecido en el Código de Comercio y normativa contable con las peculiaridades contenidas en esta Ley y normas que la desarrollen, ...».

Al tener reservada el Estado, la competencia exclusiva en materia mercantil, la regulación contable de las entidades cooperativas debía realizarse de acuerdo con las directrices marcadas por el PGC; por el Plan General de Contabilidad de pequeñas y medianas empresas; y por las resoluciones del Instituto de Contabilidad y Auditoría de Cuentas (ICAC en adelante), que les afectaran. El Real Decreto 1514/2007, en su disposición final segunda, autorizó al Ministerio de Economía y Hacienda, a propuesta del ICAC, a que adaptase las normas de registro y valoración, las normas de elaboración y la estructura, nomenclatura y terminología de las cuentas anuales a las condiciones concretas del su- 
jeto contable. Asimismo, su disposición transitoria quinta, permitió seguir aplicando las adaptaciones sectoriales y otras disposiciones en materia contable, en vigor a la fecha de publicación del Real Decreto, en todo aquello que no se opusieran a lo dispuesto en el Código de Comercio; Texto Refundido de la Ley de Sociedades de Capital; disposiciones específicas y en el propio PGC.

Las cooperativas, por ser entidades contables con características peculiares ${ }^{9}$, complementan su regulación contable con unas normas específicas publicadas por Orden Ministerial EHA/3360/2010, de 21 de diciembre, por la que se aprobaron las nuevas normas sobre los aspectos contables de las sociedades cooperativas ${ }^{10}$.

El artículo primero de dicha Orden, aprueba las nuevas normas y el artículo segundo establece su ámbito de aplicación. Se establece la aplicación obligatoria de estas normas para todas las cooperativas. En lo no regulado por ellas, deben aplicar tanto el PGC, o bien el Plan de Contabilidad de Pequeñas y Medianas Empresas, siempre que hubieran optado por ello, así como las adaptaciones sectoriales o bien las Resoluciones del ICAC, siempre que proceda.

Marca una excepción a la aplicación obligatoria de las normas, el caso de las cooperativas de crédito y el de las cooperativas de seguros. Estas dos categorías de cooperativas, deben aplicar su normativa contable específica, por lo que las normas contables de cooperativas se aplicarán, en estos dos casos, de manera supletoria y siempre en lo no regulado por su normativa propia.

La contabilidad de las cooperativas de crédito debe regirse por lo regulado en la normativa establecida para las entidades de crédito, es decir, las Circulares emitidas por el Banco de España, así como los Reglamentos de la Unión Europea que procedan. Respecto a la contabilidad de las cooperativas de seguros, deberán regularse por lo dispuesto en la normativa propia de la Ley de ordenación del seguro privado, admitiendo dicha norma, que la contabilidad de las entidades aseguradoras, se rija por sus normas específicas y en su defecto, por lo reglado en el PGC, el Código de Comercio y demás disposiciones de la legislación mercantil en materia contable. En la actualidad, disponen de un Plan Contable específico para entidades aseguradoras, aprobado mediante Real Decreto 1317/2008, de 24 de julio. Por último, siempre que la

9 Sobre la evolución del derecho cooperativo y la necesidad de preservar una identidad distinta de las cooperativas, véase Fici 2015.

10 Esta identidad no sólo las ha hecho acreedores de unas normas singulares en el ámbito contable. También se reclama una tratamiento fiscal especial por este mismo hecho (Atxabal Rada, 2016). 
cooperativa, con independencia de su clase, tuviera una sección de crédito, respecto a ésta, debería aplicarse la normativa contable específica que le corresponda y supletoriamente, las normas contables sobre cooperativas.

Las normas sobre aspectos contables de las sociedades cooperativas publicadas en el año 2010 derogaron las existentes hasta ese momento (aprobadas por Orden ECO/3614/2003). El objetivo de este nuevo precepto consistía en proporcionar unas normas que permitieran suministrar información financiera de acuerdo a los nuevos postulados contables, enmarcados en la nueva ideología de las normas internacionales de contabilidad y uno de los elementos clave fue el tratamiento contable de la cifra de capital social cooperativo, dando al capital social reintegrable la calificación de pasivo financiero y dejando en la categoría de fondos propios únicamente al capital social no reintegrable.

Este cambio de calificación contable del capital social cooperativo, condicionado ahora a su posible reintegrabilidad, tuvo su origen en la distinción entre pasivo y patrimonio neto emanada de las normas internaciones de contabilidad, en particular, de la NIC 32 «Instrumentos financieros: presentación e información a revelar» y la CINIIF 2 «Aportaciones de socios en entidades cooperativas e instrumentos similares», así como su posterior reproducción tanto en la norma de registro y valoración novena del PGC «Instrumentos financieros», como en las normas contables cooperativas de 2010.

La baja del socio en la cooperativa tiene claras consecuencias en la cifra de capital social cooperativo, por lo que a continuación analizaremos los cambios que se producen en el tratamiento contable del capital social de las cooperativas como consecuencia de la adaptación de las normas contables a la NIC 32 y la CINIIF 2.

\section{Antecedentes históricos al actual tratamiento del capital contable cooperativo}

La discusión sobre la naturaleza contable del capital social cooperativo se remonta al último tercio del siglo $\mathrm{xx}$, cuando determinados autores ya consideraban que la calificación contable de la cifra de capital social, era la de un pasivo exigible a largo plazo y no la de un recurso propio, como ocurría en las sociedades capitalistas tradicionales. ${ }^{11}$ Este

11 En Bel Durán y Fernández Guadaño (2002: 114) se citan a diversos autores como precursores del concepto de capital social como fondo ajeno. Entre otros, cita a GarcíaGutiérrez, Celaya y Ballestero. 
planteamiento, según los citados autores, era consecuencia de su carácter variable, debido a la posibilidad de que se produjeran bajas de socios con reembolso de aportaciones y de poder imputar al capital social las pérdidas contables del ejercicio. El capital social, en palabras de García-Gutiérrez, "es un préstamo especial de los socios a la sociedad, cuya duración está vinculada a la permanencia de los mismos en el proceso productivo» ${ }^{12}$.

El hecho de que se pudieran dar en cualquier momento, bajas voluntarias de socios, con la consecuente restitución de aportaciones; que las pérdidas del ejercicio se pudieran imputar a los socios, deduciéndolas del capital social; que la cifra de capital social aportada, confiriera simplemente el derecho de ser socio pero que no pudiera dar más derechos como el de voto, o la participación en beneficios; que la aportación al capital social fuera retribuida vía intereses, que a su vez se consideraban gasto deducible en la sociedad, eran algunos de los motivos que argumentaban, según estos autores, el carácter de fondo ajeno - préstamo de los socios- de la cifra de capital social.

Sin embargo, las normas contables españolas específicas para las sociedades cooperativas de 2003 (hoy remozadas por las normas de 2010), regulaban la cuenta de capital social, enunciando el principio de estabilidad como una de sus características, al mencionar "su carácter de permanencia o estabilidad, de forma que su reembolso o reducción está sometido a una serie de limitaciones impuestas por la Ley» y como otra característica que "actúa como garantía de los acreedores sociales». La antiguas normas de 2003 , calificaban el capital social cooperativo como un fondo propio, en cualquier caso, tuviera o no derecho de rescate por parte de los cooperativistas y con independencia de la posibilidad de imputarle las pérdidas sociales. Esta consideración como fondo propio fue también defendida por una buena parte de la doctrina, entre otros citamos a Vicent Chuliá (1998), Vargas Vasserot (2007), Fajardo García (2005) o Pastor Sempere (2008) como defensores de esta postura.

El profesor Vicent (1998), consideraba que las aportaciones de los socios al capital no constituían en ningún caso contratos de préstamo, sino que se trataba siempre de contratos societarios. Al realizar los socios la aportación a la cooperativa, ésta adquiría el título de propiedad de dicha aportación, incardinándose la misma en el propio contrato de sociedad, al conformarse el fondo común que exigía el artículo 1665 del Código Civil, consistente en «poner en común dinero, bienes o indus-

12 García-Gutiérrez, citado en Bel Durán y Fernández Guadaño (2002: 114) Op.cit. 
tria» (Vargas Vasserot: 2007). El fundamento de dicha opinión, parte de considerar que el socio, al causar baja en la cooperativa, no tiene derecho al reembolso exacto de la misma cantidad que aportó al entrar en la entidad, como ocurre en la restitución de préstamos, sino que tiene derecho a la liquidación de sus aportaciones, al valor que tienen en ese momento, en su caso actualizado, para evitar la pérdida de poder adquisitivo. La cantidad a reembolsar puede también minorarse por las pérdidas imputadas al socio y por las cantidades que en concepto de indemnización se puedan deducir, alegando que las bajas sean no justificadas (Vicent Chuliá1998: 24). Es decir, son aportaciones de riesgo y mientras estén en el seno de la cooperativa, sirven para responder de las deudas sociales ante acreedores externos y aún en el caso de que el socio cause baja en la cooperativa, éste seguirá respondiendo subsidiariamente de las deudas sociales durante un plazo de tiempo determinado, normalmente cinco años, mientras no exista patrimonio social suficiente.

Otra argumentación a favor de la consideración del capital como fondo propio, viene de la mano de la profesora Pastor Sempere (2008: 55), quien lo analiza desde el punto de vista del Derecho concursal, al que denomina como «tradicional banco de pruebas de los recursos propios de una sociedad». Así, si una cooperativa estuviera en situación legal de concurso y las aportaciones al capital social se calificaran contablemente como pasivos financieros, los socios pasarían a formar parte de la masa acreedora de la sociedad. El hecho de que los socios son considerados como personas especialmente relacionadas con la sociedad, en particular, aquéllos que detenten como mínimo el 10\% del capital y por tanto calificados como créditos subordinados, evidencia que, con casi absoluta seguridad, no podrán obtener el reembolso de sus aportaciones ni el de los intereses vencidos y no cobrados, ya que los créditos subordinados están por detrás de los acreedores privilegiados y de los ordinarios. Por tanto, de acuerdo con el criterio de esta autora, la Ley Concursal convierte a estas aportaciones en verdaderos recursos propios de la entidad.

En la actualidad, como ya hemos comentado, el tratamiento contable de la cifra de capital social, ha sufrido importantes cambios. Así, las actuales normas sobre aspectos contables de las sociedades cooperativas de 2010 han dado al capital social reintegrable la calificación de pasivo financiero, dejando en la categoría de fondos propios únicamente al capital social no reintegrable. Dicho cambio de concepción contable, surgió como consecuencia de las modificaciones que se produjeron en el ámbito contable internacional, y que en aras a la ansiada armonización contable internacional, fueron asumidos por la normativa mercantil y contable española. 
La clasificación de las aportaciones al capital de las cooperativas deberá distinguir entre su consideración como instrumento de patrimonio (capital-propiedad) o pasivo financiero (capital-préstamo). Ello ocasionará efectos en la presentación de las cuentas anuales, como el que afectará al balance, figurando la financiación en el patrimonio neto o en el pasivo. Por consiguiente, al plantearse la cooperativa la contabilización de la posible baja del socio, se deberá analizar previamente la calificación contable otorgada a las aportaciones realizadas por el socio. A continuación analizaremos los criterios al respecto derivados de la normativa contable internacional, para adentrarnos posteriormente en nuestras fronteras, en el PGC.

\section{Concepción contable del capital social cooperativo, según normas internacionales de contabilidad}

En el ámbito contable internacional, tanto las NIIF como sus interpretaciones, han ido en la línea de calificar al capital social cooperativo reintegrable como un pasivo financiero. Todo ello de acuerdo al principio por el cual el fondo económico de una operación prima sobre su forma jurídica, establecido en el Marco Conceptual del IASB, en su párrafo 4.6. Según éste, para clasificar contablemente una partida, debe prestarse atención a las condiciones sustanciales y a la realidad económica que subyacen en la misma y no meramente a su forma legal.

El Marco Conceptual para la preparación y presentación de los estados financieros, elaborado por el IASB, pieza clave del modelo contable de dicho organismo, no contiene referencias concretas a la aplicación de dicha normativa a las cooperativas (Bastida Vialcanet 2013: 112). El citado autor, siguiendo a Vargas Vasserot (2007), establece que la normativa contable internacional es de aplicación a las cooperativas en base a dos párrafos del Marco Conceptual en los que se incluye a las sociedades personalistas como entidades que realizan actividades industriales, comerciales o de negocios y a las que, por consiguiente, se les pueden aplicar los aspectos incluidos en el Marco Conceptual. A mayor abundamiento, tanto la NIC 32 como la CINIIF 2 mencionan expresamente a las cooperativas, no dejando lugar a dudas la aplicación de la normativa internacional a estas empresas.

El Marco Conceptual define el concepto de pasivo como una obligación presente en la empresa, surgida a raíz de sucesos pasados, a cuyo vencimiento y para cancelarla la empresa espera desprenderse de recursos que incorporan beneficios económicos; por otro lado, define patrimonio neto como la parte residual de los activos de la empresa, 
una vez deducidos todos sus pasivos. De ello se deduce que una de las condiciones esenciales para que un elemento sea pasivo, según el IASB, sería la existencia de una "obligación presente en la empresa», es decir, debería tratarse de una obligación actual.

Pero para profundizar en la calificación del capital deberemos acudir a la NIC $32^{13}$ «Instrumentos financieros: Presentación» que establece una matización adicional a la distinción entre pasivo y patrimonio neto, al enunciar los principios que califican a cualquier instrumento financiero como pasivo financiero o como instrumento de patrimonio. Según el párrafo 17 de esta norma, se calificará un instrumento como pasivo financiero siempre que exista una obligación contractual, que recaiga sobre el emisor, consistente en entregar efectivo $u$ otro activo financiero a la otra parte o intercambiar con él activos o pasivos financieros en condiciones que sean potencialmente desfavorables ${ }^{14}$. De acuerdo a dicha afirmación, las aportaciones al capital social que conlleven aparejada una obligación de entregar efectivo $u$ otro activo financiero a la otra parte, entrarían en la definición de pasivo. Esto supondría, en principio, la calificación como pasivos financieros para todas aquellas aportaciones al capital social que la cooperativa estuviera obligada a retribuir periódicamente, a un tipo de interés prefijado o variable, tuvieran o no derecho de reembolso por parte de los socios. Pero también a las aportaciones reintegrables por la mera literalidad de las mismas, al existir una obligación contractual15 (contrato de sociedad que se desarrolla en los estatutos sociales y demás reglamentos de régimen interno que pudieren existir), que recae sobre la cooperativa (emisor), consistente en entregar efectivo $u$ otro activo financiero al socio (tenedor) y que, aunque tenga la forma jurídica de capital social, en el

13 La NIC 32 se aprobó en marzo de 1995 y fue ligeramente modificada por la NIC 39 «Instrumentos financieros: reconocimiento y medición». Fue adoptada por el Reglamento 2237/2004, de 29 de diciembre, de la Comisión Europea, que modifica el Reglamento 1725/2003 por el que se adoptan determinadas Normas Internacionales de Contabilidad. Posteriormente ha sufrido varias modificaciones, introducidas bien por otras normas internacionales, bien por documentos propios emitidos por el IASB en 2007, 2008 y 2009.

14 Excepciona de este criterio a aquellas operaciones que cumplan con unas determinadas características, establecidas en los párrafos $16 \mathrm{~A}$ y $16 \mathrm{~B}$ o en los párrafos $16 \mathrm{C}$ y $16 \mathrm{D}$ de la propia NIC 32.

15 En el ámbito de la NIC 32, los términos «contratos» y «contractual» hacen referencia a un acuerdo entre dos o más partes que produce a las partes implicadas, claras consecuencias económicas que tienen poca o ninguna capacidad de evitar, ya que el cumplimiento del acuerdo es exigible legalmente. Los contratos, y por tanto los instrumentos financieros asociados, pueden adoptar una gran variedad de formas y no precisan ser fijados por escrito (NIC 32, párrafo 13). 
fondo económico es pasivo, esto es, deuda, porque existe un derecho del socio a reclamar su importe en caso de baja de la entidad (derecho de reembolso) (Vargas Vasserot 2012: 81).

Sin embargo, dejando de lado el caso especial de las aportaciones con retribución obligatoria y analizando el literal de la definición de pasivo aportada, entendemos que no encaja por completo para el caso del capital social reintegrable ya que, en el momento en que los socios realizan su aportación al capital social, no nace ninguna obligación de devolverles sus aportaciones. Los socios tienen el derecho a exigir la restitución de sus aportaciones si causan baja en la cooperativa, por consiguiente, la obligación nacerá en el momento en que los socios decidan causar baja en la entidad y ejerzan ese derecho. Sin embargo, puede ocurrir el caso de un socio que nunca decida dejar de ser cooperativista y por tanto nunca existirá la obligación de restitución de sus aportaciones. En este supuesto, al calificar contablemente la partida de capital social, en el momento de su constitución, no podríamos decir que es una obligación «actual» en la empresa surgida como consecuencia de sucesos "pasados», ya que no se ha originado dicha obligación actual. Por tanto no podría ser pasivo bajo la definición dada por el Marco Conceptual del IASB, quedando pues dicha partida incluida en el patrimonio neto de la entidad. Por el contrario, en el momento en que adquiriera firmeza el acuerdo por el que se formalizase la baja del socio y éste solicitase la restitución de sus aportaciones, se produciría un cambio en la naturaleza de esta partida, pasando ya a formar parte del pasivo.

Con posterioridad a la reforma de la NIC 32, el IFRIC elaboró una interpretación a fin de facilitar la aplicación de la NIC 32 a las sociedades cooperativas. La CINIIF 2 «Aportaciones de socios de entidades cooperativas e instrumentos similares ${ }^{16}$, se aplica a los instrumentos financieros que están dentro del alcance de la NIC 32, entre los que se incluyen las aportaciones de socios al capital de las cooperativas, que constituyen participaciones en la propiedad de estas entidades. En ella se contienen unos criterios más concretos al tiempo de calificar el capital como pasivo financiero o como instrumento de patrimonio. Así, dispone que el derecho contractual del tenedor de un instrumento financiero a solicitar el rescate no debe implicar, por sí mismo, clasificar el citado instrumento como pasivo financiero. La entidad tendrá en cuenta todos los términos

16 La interpretación CINIIF 2 se publicó el 24 de noviembre de 2004 y se inserta como anexo del Reglamento (CE) n. ${ }^{\circ} 1725 / 2003$ por el que se adoptan determinadas normas internacionales de contabilidad, mediante el Reglamento n. ${ }^{\circ}$ 1073/2005 de la Comisión, de 7 de julio. Se empieza a aplicar a partir de 1 de enero de 2005. 
y condiciones del instrumento financiero para clasificarlo contablemente. Los anteriores términos y condiciones se derivan de las leyes aplicables y los estatutos particulares de la entidad vigentes en la fecha de la clasificación. Del anterior análisis resultará el elemento sobre el que pivotará la clasificación del capital: el derecho incondicional a rechazar el rescate del capital en caso de baja del socio.

La CINIIF 2 propugna calificar como pasivo financiero las aportaciones de los socios, siempre que la entidad no tenga derecho incondicional a rechazar el rescate del capital. A tal efecto establece las siguientes concreciones:

- Las aportaciones de los socios serán pasivo financiero, si la normativa sustantiva o los estatutos sociales prohíben el rescate únicamente si se cumplen o se dejan de cumplir ciertas condiciones. La falta de liquidez $u$ otras restricciones legales, no niegan la existencia de la obligación, luego la calificación debe ser pasivo financiero.

- La prohibición incondicional al rescate podría ser absoluta o parcial. La primera es aquella que prohíbe todos los reembolsos. La segunda, supone la prohibición del reembolso de las aportaciones a los socios si éste supone que el capital descienda por debajo de un determinado nivel. Las aportaciones de los socios por encima del nivel en que se prohíbe el reembolso son pasivos.

- En algunos casos, las aportaciones sujetas a la prohibición de reembolso pueden cambiar en el tiempo. Este cambio en la prohibición de reembolso dará lugar a una reclasificación entre pasivos financieros y patrimonio neto.

En síntesis, el criterio principal para delimitar la calificación como fondo propio o como pasivo financiero del capital social de la cooperativa, sería el carácter condicional o incondicional de la reintegrabilidad de las aportaciones a los socios, ignorando otros factores como pudieran ser el derecho de voto, la eventual retribución de las aportaciones o la relación de propiedad básica.

Sin embargo, tal como hemos expuesto en trabajos anteriores (Genovart Balaguer 2013: 152-153) la interpretación CINIIF 2 presenta un punto débil: que el criterio delimitador instrumentos de patrimonio vs pasivo financiero sea el derecho de la sociedad a rechazar incondicionalmente el reembolso, entra en contradicción con la definición de pasivo del Marco Conceptual del IASB. Así, si la sociedad no tiene ese derecho incondicional, estamos ante un hecho económico que no ha generado ninguna obligación «presente» dado que los socios tienen el derecho a solicitar el rescate, pero no están obligados a ello. Ade- 
más, el concepto de pasivo según el Marco Conceptual, se fundamenta en sucesos pasados y el ejercicio del derecho de reintegro no es un suceso pasado, sino futuro. Puede ser que los socios decidan no rescatar nunca sus aportaciones. En este caso, la obligación nunca surgiría y por tanto, según el Marco Conceptual, el capital social sería considerado como un elemento del patrimonio neto de la entidad, en contraposición al criterio establecido por la CINIIF 2, que lo calificaría directamente como pasivo financiero, por no existir esa prohibición de rescate incondicional.

Por otro lado, aunque la sociedad tenga la posibilidad de rechazar su reembolso, no quiere decir que siempre ejecute dicha facultad. Es decir, puede ocurrir que los estatutos otorguen al Consejo Rector el derecho incondicional a rechazar el rescate de las aportaciones de los socios, pero la cooperativa no haya ejercido ese derecho nunca y hasta la fecha, haya restituido a los socios todas las aportaciones que les han solicitado. En este caso, siguiendo el literal de la interpretación CINIIF 2 , las restantes aportaciones seguirían siendo patrimonio neto toda vez que, aunque la sociedad no lo haya ejercido, ostenta el derecho a rechazar dichos reembolsos. Por consiguiente, el criterio internacional delimita la calificación entre pasivo o patrimonio neto atendiendo exclusivamente, a la posesión o no de un derecho incondicional a rechazar el rescate y no en el ejercicio del citado derecho.

Apuntamos como segundo punto débil de la CNIIF 2 la ausencia de un criterio de calificación contable para el caso de que la cooperativa tuviera la obligación de retribuir con intereses periódicos las aportaciones al capital social. En este caso, tanto la definición de pasivo dada por el Marco Conceptual, como la propia NIC 32, especifican que el capital será considerado pasivo, siempre que exista una obligación de entregar efectivo u otro activo financiero a otra entidad. Sin embargo, la interpretación de la norma, específica para el caso de las sociedades cooperativas, no se pronuncia ante este hecho económico, característico, por otra parte, del ámbito cooperativo.

En el seno del IASB, se están replanteando los contenidos de la NIC 32 , en lo que se refiere a la clasificación de los instrumentos financieros con características de neto. Ello es consecuencia por un lado, de que la mayoría del sector cooperativo no está conforme con los criterios de calificación contable del capital propuestos por la NIC 32 y la CINIIF 2, demandando una revisión de la normativa. Por otro lado, las innovaciones en los mercados financieros y el desarrollo de nuevos instrumentos financieros con características de patrimonio neto y de deuda, obligan a desarrollar nuevas definiciones y clasificaciones más precisas para los instrumentos financieros (Bastida Vialcanet 2013: 119). 
En el año 2008, se publicó una revisión de la NIC 32 en la que se dio entrada a la posibilidad de calificar como instrumentos de patrimonio, a aquéllos que cumplieran las condiciones de los párrafos $16 \mathrm{~A}$ y 16B de la norma, correspondientes a determinados instrumentos con opción de venta (puttable instrument), o bien los párrafos 16C y 16D, con referencia a determinados instrumentos que imponen a la entidad una obligación de entregar a terceros una participación proporcional de los activos netos de la entidad sólo en el momento de la liquidación. Dicha modificación fue también trasladada a la interpretación CINIIF 2, que se actualizó en este sentido.

La NIC 32 define un instrumento con opción de venta como aquel que proporciona al tenedor el derecho a devolver el instrumento al emisor a cambio de efectivo o de otro activo financiero o es devuelto automáticamente al emisor en el momento en que tenga lugar un suceso futuro incierto o la muerte o jubilación del tenedor de dicho instrumento. El párrafo 16A, clasifica los instrumentos con opción de venta como instrumentos de patrimonio, si y sólo si, reúnen todas las características siguientes:

a) Otorga al tenedor una participación proporcional de los activos netos de la entidad en caso de liquidación de la misma, siendo los activos netos los que se mantienen después de deducir todos los demás derechos sobre sus activos. La participación proporcional se determina:

i. Mediante la división de los activos netos de la entidad en el momento de la liquidación en unidades de importe idéntico, y

ii. La multiplicación de ese importe por el número de unidades en posesión del tenedor de los instrumentos financieros.

b) El instrumento pertenece a la clase de instrumentos que está subordinado a todas las demás clases de instrumentos. Por estar en dicha clase el instrumento:

i. No tiene prioridad sobre otros derechos a los activos de la entidad en el momento de la liquidación, y

ii. No necesita convertirse en otro instrumento antes de que esté en la clase de instrumentos que se encuentre subordinado a todas las demás clases de instrumentos.

c) Todos los instrumentos financieros de la clase de instrumentos que está subordinada a todas las demás clases de instrumentos tienen características idénticas. Por ejemplo, deben incorporar todos opción de venta, y la fórmula $u$ otros medios utilizados 
para calcular el precio de recompra o reembolso es el mismo para todos los instrumentos de esa clase.

d) Además de la obligación contractual para el emisor, de recomprar o reembolsar el instrumento mediante efectivo $u$ otro activo financiero, el instrumento no incluye ninguna obligación contractual de entregar a otra entidad efectivo $u$ otro activo financiero, o intercambiar activos financieros o pasivos financieros con otra entidad en condiciones que sean potencialmente desfavorables para la entidad, y no es un contrato que sea o pueda ser liquidado utilizando instrumentos de patrimonio propio de la entidad como establece en el subpárrafo (b) de la definición de pasivo financiero.

e) Los flujos de efectivo totales esperados atribuibles al instrumento a lo largo de su vida se basan sustancialmente en los resultados, en el cambio en los activos netos reconocidos o en el cambio en el valor razonable de los activos netos reconocidos y no reconocidos de la entidad a lo largo de la vida del instrumento (excluyendo cualesquiera efectos del instrumento).

A su vez, el párrafo 16B, enuncia lo siguiente:

Para que un instrumento se clasifique como instrumento de patrimonio, además de que el instrumento tenga todas las características anteriormente mencionadas, el emisor no debe tener ningún otro instrumento o contrato que tenga:

a) Los flujos de efectivo totales basados sustancialmente en el resultado, el cambio en los activos netos reconocidos o el cambio en el valor razonable de los activos netos reconocidos o no reconocidos de la entidad (excluyendo cualesquiera efectos de este instrumento o contrato) y

b) El efecto de fijar o restringir sustancialmente el rendimiento residual para el tenedor del instrumento con opción de venta.

A efectos de aplicar esta condición, la entidad no considerará contratos no financieros con un tenedor de un instrumento descrito en el párrafo 16A que tenga condiciones y cláusulas contractuales que sean similares a las de un contrato equivalente que pueda tener lugar entre un tenedor que no tenga el instrumento y la entidad que lo emite. Si la entidad no puede determinar que se cumple esta condición, no clasificará el instrumento con opción de venta como un instrumento de patrimonio. 
El capital cooperativo reintegrable, podría asimilarse jurídicamente a un instrumento con opción de venta, aunque, no puede precisarse con seguridad que cumpla todas las condiciones establecidas por el IASB, para clasificarlo contablemente como un instrumento de patrimonio: analizando la primera condición del párrafo 16A (a), no se cumple para el caso del capital cooperativo, debido a que en caso de liquidación de la cooperativa, los socios no tienen derecho a una participación proporcional en los activos netos de la entidad, calculada ésta en proporción al número de participaciones que tienen. A los socios, una vez satisfechas las deudas sociales y adjudicado el fondo de educación y promoción a la finalidad que corresponda, se les reintegrará únicamente el importe nominal de sus aportaciones, actualizadas en su caso y deducidas las pérdidas que les correspondieran. En ocasiones, tendrán derecho también a una participación en los fondos voluntarios reintegrables, aunque ésta se distribuirá según establezcan los estatutos, por acuerdo de Asamblea General o, en su defecto, en proporción a la actividad cooperativizada realizada por los mismos. Por consiguiente, no resulta tan claro el cálculo de la participación proporcional de cada socio en los activos netos de la entidad, y que la misma se calcule dividiendo los activos netos en unidades iguales, para multiplicar a continuación por el número de unidades que ostenta cada socio. Por el contrario, en las sociedades de capital, salvo disposición contraria en los estatutos sociales, la cuota de liquidación correspondiente a cada socio sí que será proporcional a su participación en el capital social. Tampoco cumplirá la característica (d) del párrafo 16A, en el caso de que los estatutos de la cooperativa obliguen a ésta a pagar un interés periódico a los socios por las aportaciones al capital social.

Por otro lado, los párrafos 16C y 16D corresponden a los instrumentos que imponen a la entidad una obligación de entregar a terceros una participación proporcional de los activos netos de la entidad sólo en el momento de la liquidación, por lo que, en referencia a lo comentado hasta ahora, tampoco incluye el caso del capital cooperativo.

Los organismos emisores de normas contables internacionales, el IASB y el FASB (Financial Accounting Standards Board) elaboran un proyecto conjunto que lleva por título «Instrumentos financieros con características de neto», con el objetivo de mejorar y simplificar los requisitos de información financiera de aquellos instrumentos financieros que se clasifiquen como instrumentos de patrimonio. 
Siguiendo la senda iniciada por el FASB ${ }^{17}$, el IASB emitió en febrero de 2008 un documento de discusión denominado Financial Instruments with Characteristic of Equity, en el que proponía el debate de la calificación contable de los instrumentos con características de neto estableciendo críticas a la NIC 32 en base a los tres métodos propuestos por el FASB en su documento anterior, del año 2007, para clasificar los instrumentos financieros con características de neto.

Los tres métodos propuestos por el FASB para diferenciar los elementos pertenecientes al pasivo financiero de los considerados como instrumentos de patrimonio, eran el Basic ownership approach (enfoque de propiedad básica), el Ownership settlement approach y el Reassessed expected outcomes approach. De los tres enfoques establecía como método prioritario el método de la propiedad básica que define en primer lugar los instrumentos de capital y de manera residual, las obligaciones. Este método propugna la inclusión de un instrumento en el patrimonio neto de la entidad siempre que, en caso de liquidación de la entidad y una vez satisfechas todas las obligaciones, diera derecho a su titular, a una porción de los activos netos de la empresa.

Se mantuvo en esa época el debate de la clasificación de los activos financieros con características de neto surgiendo otros métodos de clasificación como el Loss absorption approach, propuesto por un grupo de organismos emisores de normas contables de diferentes países europeos, denominado Proactive Accounting Activities in Europe Working Group. En dicho modelo, los instrumentos se calificarían como patrimonio neto siempre que asumieran una parte de las pérdidas de la sociedad ${ }^{18}$.

En el año 2010, el IASB paralizó temporalmente el proyecto de debate, al reconocer que tenía importantes limitaciones de capacidad y no podía dedicar el tiempo necesario a deliberar sobre las cuestiones de este proyecto, en el corto plazo. El proyecto fue reactivado en 2012, únicamente por el IASB y supeditado al proyecto de Marco Conceptual (Zubiaurre Artola, Andicoechea Arondo y Saitua Iríbar 2015: 185) Sin embargo, puede observarse, haciendo un seguimiento de su plan de trabajo, que el Comité se estaba replanteando su posición inicial, como demostró en la publicación de su Boletín mensual, en la edición de marzo de 2009.

17 El FASB emitió el 30 de noviembre de 2007 un documento de trabajo que lleva por título «Preliminary Views on Financial Instruments with Characteristics of Equity» que sometió a consulta pública hasta el 30 de mayo de 2008.

18 Sobre los diferentes modelos propuestos ver López Espinosa 2008, donde se analizan los efectos de la aplicación de los citados métodos de clasificación de los instrumentos financieros en las entidades cooperativas. 
En dicho Boletín, el Comité puso de manifiesto algunas de las decisiones provisionales, adoptadas en este sentido. El cambio de criterio comentado, seguía la línea del enfoque de la propiedad básica, para delimitar si un instrumento se califica como pasivo o como instrumento de patrimonio. En este sentido, determinados instrumentos financieros que, en un principio pudieran parecer considerados como pasivos financieros, se deberían calificar en realidad como instrumentos de patrimonio. Entre ellos destacan aquellos instrumentos de propiedad que son obligatoriamente reembolsables aunque únicamente en caso de muerte o retiro. El término «retiro», retirement, es matizado y se utiliza en términos generales como jubilación, cese o renuncia a ser socio o a ser miembro de una cooperativa.

Zubiaurre Artolo y Andicoechea Arondo (2010: 8) opinan en su trabajo que se debería mantener el capital social reintegrable como fondos propios, aludiendo a que el fondo de la relación contractual del socio con la cooperativa es de vinculación duradera y estable. El socio, en virtud del principio de libre adhesión y baja voluntaria, puede darse de baja en cualquier momento, pero la intención inicial al aportar el capital, es la de vinculación duradera y permanente. Además, la aportación de capital le permite obtener dos de las propiedades básicas de los instrumentos de neto, poder político y acceso al excedente. Proponen pues dos alternativas, mantener todo el capital como fondos propios a la vez que incorporar en las cuentas anuales, específicamente en la memoria de las cuentas anuales, información sobre las previsiones que se conocen de reembolso de capital en un horizonte temporal próximo; o bien, realizar una reclasificación anticipada como pasivo de aquella parte de capital afectada por la probable obligación de reembolso a determinados socios. ${ }^{19}$

Una vez establecida la posición internacional sobre la calificación contable del capital social cooperativo, analizamos a continuación la postura adoptada por la legislación contable española.

\section{Concepción contable del capital social cooperativo, según la normativa española}

La normativa contable española aboga por el principio por el cual, debe primar el fondo económico de la operación, sobre la forma jurídica que detenta. El artículo 34.2 del Código de Comercio, modificado por la Ley 16/2007 y siguiendo las directrices marcadas por las NIIF,

19 Ver también los comentarios, en este sentido de Pastor Sempere 2011: 396. 
afirma que, en la contabilización de las operaciones se atenderá a la realidad económica de las mismas y no sólo a su forma jurídica.

Otra de las modificaciones realizadas por la Ley 16/2007, en línea con la interpretación CINIIF 2, es la reforma del artículo 45 de la Ley cooperativa estatal, añadiendo como posibilidad legal que el Consejo Rector rechace incondicionalmente determinados reembolsos de aportaciones en el caso de baja de socios ${ }^{20}$. También prevé la posibilidad de que los estatutos impongan un porcentaje de capital social por debajo del cual los reembolsos estén condicionados a un acuerdo favorable del Consejo Rector. Este porcentaje de capital, puede o no ser igual al capital social mínimo establecido. En este caso, y de acuerdo con la interpretación CINIIF 2, dicho porcentaje de capital sería considerado patrimonio neto y el capital que estuviera por encima de esa cifra, daría lugar a un pasivo financiero. La variación posterior del porcentaje no reintegrable ocasionaría transferencias entre pasivo financiero y patrimonio neto y viceversa.

En el ámbito de la normativa contable, el actual PGC adopta la filosofía del IASB al definir los conceptos de pasivo y de patrimonio neto en la parte del Plan dedicada al Marco Conceptual, del siguiente modo:

«Pasivo: obligaciones actuales surgidas como consecuencia de sucesos pasados, para cuya extinción la empresa espera desprenderse de recursos que puedan producir beneficios o rendimientos económicos en el futuro. A estos efectos, se entienden incluidas las provisiones.

Patrimonio neto: constituye la parte residual de los activos de la empresa, una vez deducidos todos sus pasivos. Incluye las aportaciones realizadas, ya sea en el momento de su constitución o en otros posteriores, por sus socios o propietarios, que no tengan la consideración de pasivos, así como los resultados acumulados y otras variaciones que le afecten.»

20 Dicha posibilidad de rechazo incondicional al reembolso ha sido incluida también en la totalidad de leyes autonómicas, en particular, la de Andalucía (art. 60.1 Ley 14/2011), Asturias (art. 4 Ley 4/2010), Aragón (art. 48 Ley 9/1998, reformado por Ley 4/2010, de 22 de junio), Castilla León (art. 59 Ley 4/2002, reformado por Ley 6/2011), Cataluña (art. 55bis, introducido por Decreto Ley 1/2011, de 15 de febrero), Comunidad Valenciana (art. 55.1 Ley 8/2003, modificado según Ley 16/2010, de 27 de diciembre), Euskadi (art. 57.1 Ley 4/1993, reformado por Ley 8/2006, de 1 de diciembre), Extremadura (art. 49 Ley 2/1998 reformada por Decreto Ley 1/20119, Galicia (art. 58 Ley 5/1998, reformado por Ley 14/2011), Baleares (art. 69 Ley 1/2003, reformado por Ley 5/2011), Murcia (art. 64 Ley 8/2006, reformado por Ley 4/2011), Navarra (art. 45.1 Ley 14/2006), La Rioja (art. 61.1 Ley 4/2001, reformado por Ley 6/2009, de 15 de diciembre), Castilla La Mancha (art. 74.8 Ley 11/2010) y Madrid (art. 49.1 Ley 4/1999, modificado por Ley 10/2009, de 23 de diciembre). 
Por otro lado, la segunda parte del PGC correspondiente a las Normas de registro y valoración (en adelante NRV), que desarrollan las disposiciones contenidas en el Marco Conceptual y son de aplicación obligatoria para las empresas, en su norma novena, referida a los instrumentos financieros y particularmente, en el epígrafe tercero, habla de los pasivos financieros en concordancia con lo expuesto por la NIC 32:

«Los instrumentos emitidos se clasificarán como pasivos financieros, en su totalidad o en una de sus partes, siempre que de acuerdo con su realidad económica supongan para la empresa una obligación contractual, directa o indirecta, de entregar efectivo u otro activo financiero, o de intercambiar activos o pasivos financieros con terceros en condiciones potencialmente desfavorables, tal como un instrumento financiero que prevea su recompra obligatoria por parte del emisor, o que otorgue al tenedor el derecho a exigir del emisor su rescate en una fecha y por un importe determinado o determinable, o a recibir una remuneración siempre que haya beneficios».

Según dicha definición, el capital social de las cooperativas, en la medida que tuviera derecho de rescate por los socios, sería considerado como pasivo financiero. En este sentido, se consideran como pasivo financiero, dos situaciones específicas que se producen en las cooperativas:

- Aquel instrumento que «otorgue al tenedor el derecho a exigir del emisor su rescate en una fecha y por un importe determinado o determinable». Si las aportaciones son reembolsables, el socio cooperativista tiene el derecho a exigir de la cooperativa el rescate de sus aportaciones en una fecha y por un importe, no determinados de antemano, pero sí determinables. Puede o no ejercitarlo, pero el derecho lo tiene desde que realiza su aportación. Bajo este punto de vista, las aportaciones al capital social cooperativo que la sociedad no pudiera prohibir incondicionalmente su rescate, podrían considerarse, de inicio, como pasivos financieros, aunque no cumpla exactamente con la definición de pasivo, ya que todavía no se habría generado ninguna obligación.

Las NRV integradas en el PGC desarrollan las disposiciones contenidas en su Marco Conceptual. Por tanto, en caso de conflicto, como es el caso que nos ocupa, debe prevalecer 
la NRV frente al Marco Conceptual. La Asociación Española de Contabilidad y Administración de Empresas (AECA), publicó en el mes de septiembre de 2008 un Documento, el número 25 , en el que trataba la problemática de la calificación contable del capital Cooperativo, dándole el tratamiento de pasivo financiero siempre que existiera un derecho del socio a requerir su reembolso. ${ }^{21}$

- Aquel instrumento que "otorgue al tenedor el derecho a recibir una remuneración siempre que haya beneficios». Al tener derecho el socio cooperativista, si así se establece en los estatutos o en Asamblea General, a la retribución vía intereses de las aportaciones desembolsadas, esta condición se cumplirá en las cooperativas. El derecho al cobro de intereses es independiente del derecho o no a exigir el rescate de sus aportaciones. Siguiendo este criterio, toda aportación de socios que tuviera derecho a la retribución vía intereses, aun cuando fuera limitada a la existencia de beneficios, sería considerada como pasivo financiero.

La Norma segunda sobre aspectos contables de las sociedades cooperativas de 2010, califica contablemente al capital social como patrimonio neto, pasivo o instrumento financiero compuesto, en función de las características de las aportaciones de los socios o partícipes. La consideración como pasivo financiero será residual, es decir, serán pasivos financieros aquellos supuestos que no puedan ser ni patrimonio neto, ni instrumento financiero compuesto ${ }^{22}$. Por otro lado, serán fondos propios aquellas aportaciones cuyo reembolso pueda ser rehu-

21 Ver AECA: Documento AECA. Principios Contables, número 25. «Calificación contable de Instrumentos Financieros: Distinción Pasivo Patrimonio Neto». Septiembre 2008. 1. ${ }^{a}$ edición. Páginas 43, 44 y 45.

22 Se producirá de este modo, la bifurcación del instrumento financiero, que ya viene recogida en la NIC 32, párrafo 28 . El concepto de bifurcación es una aplicación de la metodología de valoración financiera que se ha venido desarrollando desde los años sesenta, consistente en la descomposición de las operaciones financieras en sus diferentes componentes. Cada uno de estos componentes se valorará por separado. Dicha valoración está basada en la hipótesis de no arbitraje, según la cual el valor de la totalidad del instrumento tiene que ser igual a la suma de los componentes que racionalmente constituyen el instrumento que se valora. Dicha hipótesis, que aparece en el desarrollo de modelos tan extendidos como el Capital Asset Pricing Model, la Arbitrage Pricing Teory o los modelos de valoración de opciones de Black, Scholes y Merton, es la base racional del concepto de bifurcación. Puede verse un análisis crítico y una propuesta alternativa a la aplicación de la bifurcación en las normas contables en el artículo de Sebastián Castro (2010). 
sado incondicionalmente por el Consejo Rector o la Asamblea General, siempre que no obliguen a la cooperativa a pagar una remuneración obligatoria al socio y el retorno sea discrecional. Es decir, si la remuneración al socio (mediante el pago de intereses periódicos o el pago de retornos cooperativos) es discrecional, al no existir ninguna obligación por parte de la empresa de remunerar al socio, la aportación seguiría formando parte de los fondos propios de la compañía. En este caso, los requisitos para calificar a las aportaciones al capital social como instrumento de patrimonio son tres, que la cooperativa pueda rehusar incondicionalmente el reembolso, unido a que tanto la retribución del capital vía intereses como el retorno cooperativo, no tengan carácter preceptivo.

Si la remuneración fuera obligatoria, aunque existiera el derecho por parte de la cooperativa a rechazar incondicionalmente el reembolso, la aportación no podría calificarse en su integridad como un instrumento de patrimonio, sino que se calificaría como un instrumento financiero compuesto. Por otro lado, si la entidad no pudiera rehusar el reembolso, aunque la remuneración, vía intereses o retornos cooperativos, fuera discrecional, también estaríamos ante un instrumento financiero compuesto.

Sin embargo, a fin de no complicar en exceso las valoraciones, las normas contables establecen que aquellas aportaciones al capital que sean calificadas como instrumento financiero compuesto, deberán reconocerse contablemente como verdaderos pasivos financieros. Ello es debido a que, en dichos instrumentos financieros compuestos, el intentar separar la valoración económica del componente de pasivo de la valoración del componente de patrimonio, resultaría arduo complicado. Argumentan dicho razonamiento por el carácter particular de la actividad cooperativa, por el cual, la remuneración de las aportaciones que realizan los socios a la misma es difícil de valorar, al no poder compararse con la rentabilidad que podría ofrecer otra empresa, con la misma configuración de riesgo. El socio, por el hecho de aportar capital a la cooperativa, tiene derecho no sólo a la retribución financiera, sino que le permite, además, poder participar en la actividad cooperativizada, último aspecto que resulta difícil de valorar económicamente y que no aparece en otras entidades mercantiles.

Así, atendiendo a que la cooperativa es una sociedad especial, las normas consideran que las actuaciones que en ella se realizan no pueden compararse con actuaciones similares ante otras empresas, por lo que al estar ante un mercado singular, los precios de las operaciones que allí se realizan, se consideran como la mejor estimación del valor razonable de dichas operaciones. Por consiguiente, a efectos de valorar 
contablemente las aportaciones, se calificarán en dos grupos: aportaciones consideradas pasivo financiero y aportaciones que forman parte del patrimonio neto de la entidad.

Aunque en las normas contables el criterio delimitador de la concepción pasivo-patrimonio neto, sea la posibilidad de rehusar el reembolso junto con el carácter preceptivo o no de las retribuciones periódicas, el ICAC, en contestación a la consulta número 7 publicada en septiembre de 2011 en el BOICAC 87, acercó posturas con el último criterio barajado por el IASB23, por el cual, determinados instrumentos financieros que en un principio pudieran parecer pasivos por tener derecho de reembolso, se deberían calificar como instrumentos de patrimonio. En la consulta afirma que, en los supuestos en los que el socio no pueda continuar desarrollando la actividad económica de la cooperativa, siempre que el motivo sea por una imposición legal, el derecho de reembolso de las aportaciones no implicará que el instrumento se califique como pasivo. Entre los supuestos establecidos por imposición legal, considera la incapacidad y la jubilación, poniendo a modo de ejemplo el caso de las cooperativas de trabajo asociado. Por tanto, si el socio se da de baja de la cooperativa, con derecho al reembolso de sus aportaciones y no hay ningún motivo de baja que sea impuesto legalmente, sino que la baja es por su propia voluntad, se califique o no ésta como justificada, las aportaciones serán pasivos financieros. Únicamente se considerarían fondos propios, si la entidad tuviera un derecho incondicional a rechazar el rescate por cualquier motivo, excluido el caso de jubilación o incapacidad, ya que en estos dos últimos casos, aunque el socio pudiera darse de baja con derecho al reembolso de sus aportaciones, éstas se contabilizarían en los fondos propios. Es necesario hacer hincapié en que el IASB al referirse al "retirement» considera supuestos como la jubilación, pero también incluye el cese o renuncia a ser socio de la entidad. Por tanto, el IASB va más allá que el ICAC en esta consulta, replanteándose si debe mantener todo el capital social como instrumento de patrimonio, al considerar que la finalidad del socio es la permanencia en la empresa.

La postura que parece que va a mantener el IASB, podría ser más acertada que la mantenida en la actualidad por el ICAC, siempre que la finalidad inicial del socio fuera la de permanencia ilimitada en la cooperativa. Si el socio, en el momento de ingresar en la entidad, manifestara su intención de mantenerse por un periodo de tiempo

23 Ver Boletín del IASB de marzo de 2009, ya comentado anteriormente. 
limitado, sus aportaciones se considerarían como pasivo financiero, desde sus inicios y sobre ello, no hay confusión. En cambio, si la finalidad fuera la permanencia ilimitada, resulta conveniente considerar el capital social como patrimonio neto, ya desde el momento de la aportación inicial, aunque posteriormente se produjera su reembolso, por baja del socio.

En esta controvertida calificación contable del capital, hay otro hito a destacar. Nos referimos a la respuesta del ICAC a la consulta número 3, publicada en el BOICAC número 89, en marzo de 2012, cuando se reconoce que el «derecho del socio reconocido en el artículo 348.bis LSC es una pura y simple expectativa de derechos sin sustancia jurídica equiparable a la de un verdadero derecho de crédito y, en consecuencia, no puede concluirse que origine desde un punto de vista contable el reconocimiento de un pasivo». Se revela así la incongruencia que venimos argumentando entre el planteamiento de la NRV 9. ${ }^{a}$ del PGC y la definición y criterio de reconocimiento de un pasivo de su propio Marco Conceptual y quizá puede interpretarse como otra aproximación a la que parece será la solución que adopten el IASB y el FASB. Y mientras ello ocurra, reclamamos desde aquí una resolución del ICAC que arroje luz a este asunto tan vidrioso.

Una vez adaptada la normativa contable y mercantil a los nuevos postulados internacionales, se les dio a las cooperativas un periodo transitorio, a fin de que procedieran a adaptar sus estatutos, siempre que quisieran mantener el capital en el patrimonio neto de la entidad, atribuyendo al Consejo Rector el derecho incondicional a rehusar el reembolso del capital en caso de baja del socio, siempre que con anterioridad, las comunidades autónomas hubieran aprobado la reforma procedente en la legislación cooperativa, que otorgara dicha potestad al Consejo Rector. En la actualidad, la totalidad de las comunidades autónomas han realizado los citados cambios en su legislación, a fin de adaptarla a las prerrogativas contables. Las cooperativas, por su lado, han ido procediendo a realizar las modificaciones estatutarias oportunas para que la totalidad, o una buena parte del capital social, pueda seguir formando parte de los fondos propios de la sociedad. En la Ley nacional de cooperativas, así como en la mayoría de leyes autonómicas, se permite que la Asamblea General acuerde la transformación obligatoria de las aportaciones con derecho de reembolso en caso de baja, en aportaciones cuyo reembolso pueda ser rehusado incondicionalmente por el Consejo Rector, o la transformación inversa (art. 45.1LC).

A continuación se expone un cuadro, que resume la calificación contable que deben tener las aportaciones de socios al capital social 
de la cooperativa, atendiendo tanto al criterio de exigibilidad expuesto en las NRV del actual PGC, como a las definiciones de pasivo financiero y patrimonio neto encuadradas en su Marco Conceptual, incluyendo las especificaciones que detallan las normas contables específicas para cooperativas.

Se diferencian dos momentos en el tiempo: la calificación contable que se le daría a la cifra de capital en el momento en que los socios realizan sus aportaciones y la del momento en el que los socios causan baja en la cooperativa y se les restituyen, o no, sus aportaciones, dependiendo de que la cooperativa tuviera o no el derecho a prohibir incondicionalmente su rescate. Todo ello, teniendo en cuenta si la entidad tiene obligación de retribuir las aportaciones o de repartir retornos, o si dicha retribución o reparto de retornos es discrecional.

Para otorgar el carácter de patrimonio neto o bien de pasivo financiero, se han considerado tanto las definiciones dadas por el Marco Conceptual y la NRV 9. ${ }^{a}$, como la calificación contable especificada en las normas sobre aspectos contables de las sociedades cooperativas de 2010, en particular:

a) En el Marco Conceptual se define el concepto de pasivo, como «obligación actual surgida como consecuencia de sucesos pasados». En la tabla expuesta, se analiza si existe esa obligación actual, en el momento en el que los socios realizan sus aportaciones y si existe en el momento en el que los socios causan baja en la cooperativa.

b) Tanto la NRV 9. ${ }^{a}$ como las NACSC 2010 van en el mismo sentido. La NRV 9. ${ }^{a}$, clasifica a los instrumentos emitidos, como pasivos financieros, si «otorgan al tenedor el derecho a exigir del emisor su rescate en una fecha y por un importe determinado o determinable...» Debería enjuiciarse si existe ese derecho del tenedor en el momento de realizar las aportaciones, o bien en el momento en el que los socios causan baja de la cooperativa. Pero también debería tenerse en cuenta si, con independencia del derecho a exigir el rescate o no exigirlo, la cooperativa tiene o no la obligación de pagar una retribución al socio y saber si el retorno existe y si es o no, discrecional. 


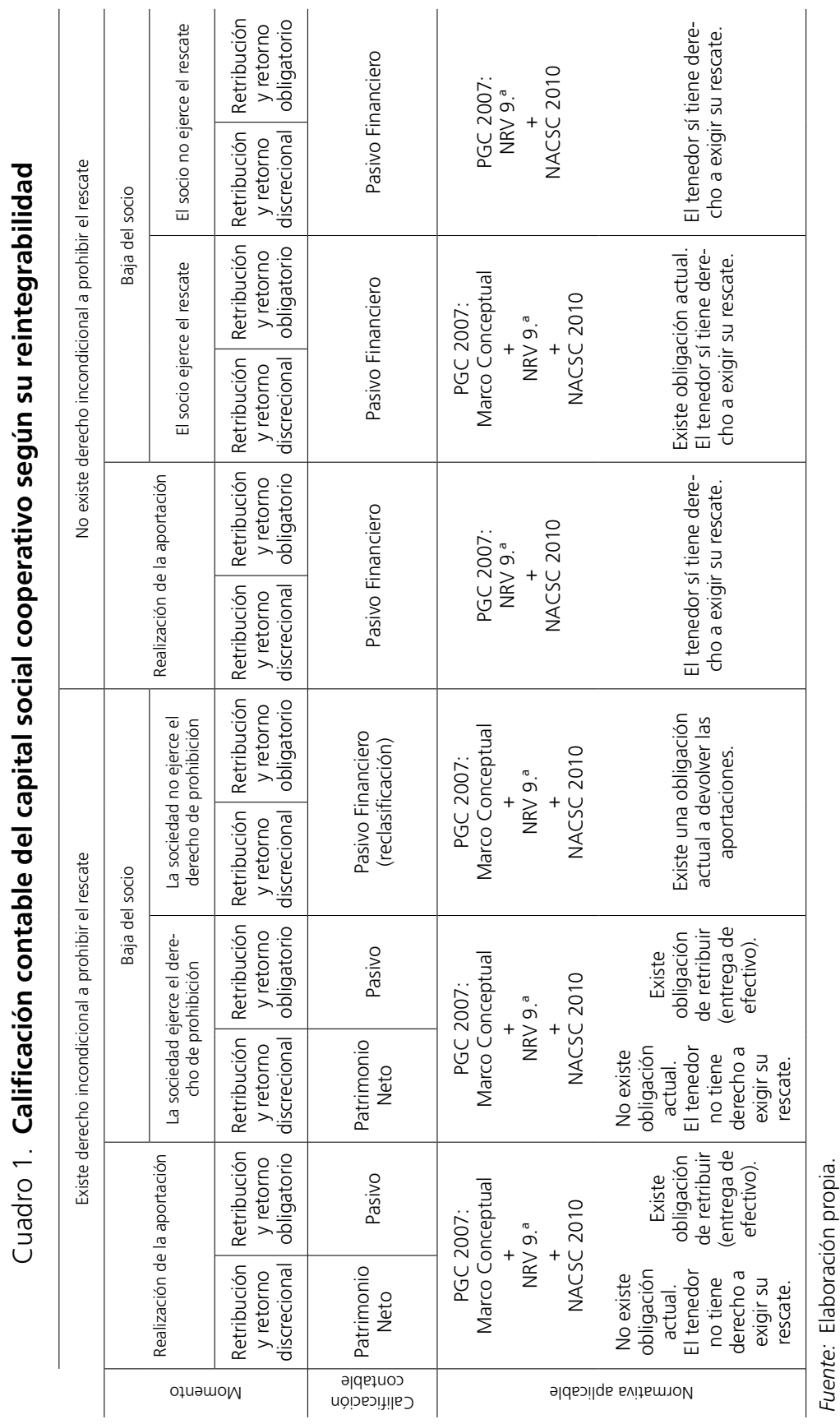


Hasta el momento, nos hemos centrado en el carácter reintegrable o no de las aportaciones como variable dicotómica. Para concluir este apartado, queremos tratar dos cuestiones más: la determinación de un porcentaje del capital social cuyo reembolso queda condicionado y el caso del capital rotatorio.

La legislación cooperativa nacional dispone que los estatutos puedan prever que cuando en un ejercicio económico el importe de la devolución de las aportaciones supere el porcentaje de capital social que en ellos se establezca, los nuevos reembolsos estén condicionados al acuerdo favorable del Consejo Rector. El ICAC ha tomado postura respecto al tratamiento contable del capital en estas circunstancias, en su consulta número 6 del BOICAC número 94 del año 2013. El Instituto manifiesta que, «si en los estatutos se condiciona el reembolso de las aportaciones al acuerdo favorable del Consejo Rector, cuando se haya superado un determinado porcentaje del capital social existente el primer día de cada ejercicio económico, cada año, en todo caso, puede llegar a reembolsarse ese porcentaje, lo que tendencialmente originará que transcurrido un determinado número de ejercicios la práctica totalidad de las aportaciones al capital social se pueden haber reembolsado por la mera previsión estatutaria en tal sentido. Es decir, la simple referencia al capital social existente al inicio del ejercicio pondría de manifiesto que todas las aportaciones son exigibles de forma diferida en el tiempo y, en consecuencia, que la totalidad del capital social debe contabilizarse como un pasivo». Una vez más hemos de manifestar nuestra discrepancia con el ICAC. Entendemos que esta respuesta va en contra del concepto de pasivo incluido en nuestro Derecho contable, pues la alusión a la exigibilidad en forma diferida en el tiempo, va en contra del carácter «presente» que reclama el Marco Conceptual a las obligaciones.

Merece especial atención, dada su amplia proliferación en los sectores cooperativos, principalmente en el sector cooperativo agrario, el llamado capital rotativo o rotatorio. Los socios realizan las aportaciones anuales al capital social, aunque basándose en la participación que tienen, anualmente, en la actividad cooperativizada. Al recibir la cooperativa las aportaciones anuales, se le reembolsan al socio las aportaciones realizadas por él, en periodos anteriores. Aunque el momento en que se inician las devoluciones debe venir determinado por la Asamblea General. Vargas Vasserot (2012: 92) explica que «el capital rotatorio funciona acumulando capital social hasta que se alcance un nivel adecuado de capitalización, a partir de ese momento cuando se reciban nuevas aportaciones al capital social que incrementen el fondo por encima de la cantidad necesaria, el exceso se reembolsa a los socios más 
antiguos que reciben sus aportaciones actualizadas. De esta forma el capital queda siempre dentro de unos márgenes de seguridad, ya que los reembolsos se detienen cuando el capital acumulado llega a ese mínimo necesario (estatutario o fijado por ley), y los socios que ya han sido reembolsados pueden, o deben, hacer nuevas aportaciones al capital social».

Las aportaciones que realizan los socios por el procedimiento del capital rotativo, pueden determinarse de diferentes maneras. Polo Garrido y Romero Civera (2011), diferencian tres procedimientos. El primero consiste en establecer un importe, normalmente medido en porcentaje, sobre el valor de liquidación anual de la cosecha. Otro método parte de calcular un valor económico, referido a las unidades físicas aportadas por los socios o comercializadas a través de la cooperativa. El último procedimiento trata de calcular un valor, referido a una unidad de superficie productiva, adscrita a una cooperativa. Williamson (1987: 4 y ss.) señala la existencia de innumerables variantes al tiempo de configurar el capital rotatorio en las cooperativas agrarias. Así, en ocasiones los socios reciben la totalidad de lo que aportaron y tienen que hacer nuevas aportaciones para poder continuar siendo miembros usuarios de la cooperativa. En otras ocasiones el capital social no se dota con aportaciones de los socios, sino con los excedentes repartibles, lo que implica que la dotación de cada socio sea proporcional a la actividad cooperativizada. También es frecuente encontrar un capital rotatorio a medio plazo y otro a largo plazo, y que el socio cada año vaya recibiendo así mayores porcentajes de lo que entregó, hasta que alcance una determinada edad (normalmente próxima a la jubilación), en la que puede exigir el resto de sus aportaciones. Si el socio lo desea, también puede abandonar la sociedad antes, si bien en este caso se limita el derecho de reembolso tanto en cuantía (puede no recibir todo lo que aportó), como en el tiempo (se establecen ciertos plazos para poder rescatar esas aportaciones).

En el caso del capital social rotatorio, las devoluciones de aportaciones a los socios, no dan lugar por sí mismas a la calificación contable del capital como pasivo financiero, toda vez que van acompañadas de nuevas aportaciones al capital, calculadas éstas según el uso actual que está haciendo el socio de la actividad cooperativa. El capital social, en este caso, es bastante estable, ya que, aunque varíe de manos (unos años aportarán más capital unos socios y otros años lo harán otros), el cómputo global se mantiene con pocas variaciones. 


\section{Conclusiones}

Las modificaciones acaecidas en el ámbito contable internacional, y que fueron asumidas por la normativa mercantil y contable española, en orden al tratamiento contable del capital social cooperativo, prevén la calificación contable del capital como pasivo financiero o como fondo propio, atendiendo fundamentalmente a la posibilidad de que el socio pueda causar baja en la cooperativa, lo que preocupó profundamente al sector ante el temor de una pérdida de imagen financiera que lastrara sus posibilidades de financiación.

Consideramos que tanto el planteamiento de la NIC 32 como el de la CINIIF 2 al tiempo de calificar el capital social cooperativo como pasivo, tienen la misma falla: entran en contradicción con la definición de pasivo del Marco Conceptual.

Siguiendo la trayectoria iniciada por el FASB, el IASB está en un proceso de cambio de criterio. En nuestra opinión todo apunta a que, de acuerdo al enfoque de la propiedad básica y el criterio de voluntad de permanencia ilimitada del socio en la entidad, la regulación internacional futura podría prever la calificación de la totalidad del capital social como fondo propio. Este planteamiento nos parece más acertado que el vigente hogaño. Si el socio accede a la cooperativa con la intención de mantenerse por un periodo de tiempo limitado, sus aportaciones se considerarían como pasivo financiero, desde sus inicios y sobre ello, no cabe duda. Empero, si la voluntad del socio fuera permanecer en el seno de la cooperativa por tiempo indefinido, resulta conveniente considerar el capital social como patrimonio neto, ya desde el momento de la aportación inicial, aunque posteriormente se produjera su reembolso, por baja del socio.

En cuanto a la normativa española, en nuestra opinión, si la voluntad del socio es permanecer por tiempo indefinido en sede de la cooperativa, las NACSC 2010 y la NRV 9. ${ }^{a}$ del PGC, debieran situar estas aportaciones al capital en los fondos propios del balance. De este modo, se suprimiría la vigente discordancia entre dichas Normas y la definición y criterio de reconocimiento de un pasivo del Marco Conceptual del PGC, al no existir una obligación actual ya que ésta depende de un suceso futuro.

Esta tendencia puede observarse en la doctrina del ICAC, establecida en las consultas publicadas en los BOICAC números 87 y 89 , por la cual, determinados instrumentos financieros que en un principio pudieran parecer pasivos por tener derecho de reembolso, se deberían calificar como instrumentos de patrimonio, y de otra parte que, mientras que el socio no reclame su salida de la sociedad, el pasivo no ha na- 
cido, manteniéndose mientras tanto el capital en los fondos propios. Si en un futuro el socio ejerciera su derecho de salida de la cooperativa, sería entonces cuando surgiría el pasivo, debiendo efectuarse en ese momento una reclasificación del capital social.

El hecho de considerar el capital contablemente como pasivo supone otras consecuencias que han sido muy temidas ab initio por el sector cooperativo. En principio es obvio que empeorarán los ratios de endeudamiento y solvencia. Pese a ello, consideramos que esto no debiera variar el juicio de los analistas financieros. En primer lugar, porque la mayoría de cooperativas son Pymes y por ello las entidades crediticias suelen pedir garantías personales a los socios con independencia del balance de la entidad. Y por último, cierto es que la normativa contable vigente no ha modificado para nada el carácter reintegrable del capital, que hasta ahora ya lo había sido. Luego los analistas de riesgos debieran tener amplitud de miras al analizar estas sociedades. También se ha escrito mucho sobre la modificación al alza del riesgo de insolvencia empresarial desde el punto de vista del concurso de acreedores. Pese al empeoramiento de los ratios, la cooperativa puede tener recursos suficientes para seguir atendiendo sus obligaciones. Y si lo anterior no fuera cierto, el motivo no obedecerá a la reclasificación del capital, la causa será bien distinta y se hubiera producido igualmente si el capital continuara en el patrimonio neto del balance. Ergo, aseveramos, que la calificación como pasivo del capital, no supondrá consecuencia alguna en este sentido.

\section{Bibliografía}

ASOCIACIÓN ESPAÑOLA DE CONTABILIDAD Y ADMINISTRACIÓN DE EMPRESAS (AECA), 2008: Documento Principios Contables, 25. "Calificación contable de Instrumentos Financieros: Distinción Pasivo Patrimonio Neto». Madrid.

ATXABAL RADA, Alberto, 2016: "La identidad cooperativa como justificación de un tratamiento fiscal diferenciado». Boletín de la Asociación Internacional de Derecho Cooperativo, 50: 285-307.

BASTIDA VIALCANET, Ramón, 2013: «Efectes económics de la primera aplicación de les normes comptables adaptades a la NIC 32 i la CNIIF 2 a les cooperatives». Tesis doctoral. Universidad Rovira i Virgili.

BEL DURÁN, Paloma y FERNÁNDEZ GUADAÑO, Josefina, 2002. "La financiación propia y ajena de las sociedades cooperativas». CIRIEC-España, Revista de Economía Pública, Social y Cooperativa, 42:101-130.

$\mathrm{FICl}$, Antonio, 2015. "Tendencias y perspectivas del derecho cooperativo en el contexto global y la supervisión como oportunidad para el sector de la economía solidaria». Boletín de la Asociación Internacional de Derecho Cooperativo, 49: 223-249. 
FAJARDO GARCÍA, Isabel Gemma, 2005: "La masa activa y pasiva en el concurso de cooperativas». CIRIEC-España, Revista jurídica de economía social y cooperativa, 16: 9-54.

GENOVART BALAGUER, Juana Isabel, 2013: «Aspectos económico-contable de las sociedades cooperativas». Tesis doctoral. Universitat de les Illes Balears.

INSTITUTO DE CONTABILIDAD Y AUDITORÍA DE CUENTAS (ICAC), 2002: «Informe sobre la situación actual de la contabilidad en España y líneas básicas para abordar su reforma. Libro Blanco para la reforma de la contabilidad en España». Madrid.

INSTITUTO DE CONTABILIDAD Y AUDITORÍA DE CUENTAS (ICAC), 2011: Consulta número 7 BOICAC n. ${ }^{\circ} 87$ «Sobre si las aportaciones de los socios al capital de una sociedad cooperativa pueden calificarse como fondos propios, cuando sean exigibles única y exclusivamente en el caso de baja obligatoria por incapacidad o jubilación».

INSTITUTO DE CONTABILIDAD Y AUDITORÍA DE CUENTAS (ICAC), 2012: Consulta número 3 BOICAC n. 89 «Sobre el tratamiento contable del derecho de separación del socio regulado en el artículo 348.bis del texto refundido de la Ley de Sociedades de Capital (TRLSC), aprobado por el Real Decreto Legislativo 1/2010, de 2 de julio».

INSTITUTO DE CONTABILIDAD Y AUDITORÍA DE CUENTAS (ICAC), 2013: Consulta número 6 BOICAC n. 94 «Sobre la consideración de patrimonio neto o pasivo financiero de determinadas aportaciones al capital social de una cooperativa».

LÓPEZ ESPINOSA, Germán 2008: «La distinción entre patrimonio y deuda». Incluido en «Fundamentos teóricos y prácticos del nuevo Plan General Contable.» Editorial Aranzadi, 979-994. Navarra.

PASTOR SEMPERE, María del Carmen, 2008: «El capital social en la sociedad cooperativa: situación actual y apuntes para una reforma». Revista de Derecho procesal civil y mercantil, 50: 44-58.

PASTOR SEMPERE, María del Carmen, 2011: «Efectos jurídico-societarios tras la entrada en vigor de la Orden EHA/3360/2010, de 21 de diciembre, por la que se aprueban las normas sobre los aspectos contables de las sociedades cooperativas (BOE de 29 de diciembre de 2010). ¿Podemos seguir considerando el capital social como elemento integrante del patrimonio neto contable?». Revista de derecho de sociedades, 36 : 387-399.

POLO GARRIDO, Fernando, ROMERO CIVERA, Agustín, 2011: «El capital retornable y rotativo en las cooperativas: aspectos financieros». Comunicación presentada en el Encuentro de Institutos y Centros Universitarios de Investigación en Economía Social ENUIES 2011. Valencia.

SEBASTIÁN CASTRO, Francisco, 2010: "Las fuentes de financiación en la contabilidad. Una propuesta alternativa». Revista Contabilidad y Tributación 331: 113-150.

VARGAS VASSEROT, Carlos, 2007: «Los previsibles efectos de la NIC 32 en el sector cooperativo». REVESCO. Revista de Estudios Cooperativos 91:120-159. 
VARGAS VASSEROT, Carlos, 2011: «Aportaciones exigibles o no exigibles: ésa es la cuestión». CIRIEC-España. Revista jurídica de economía social y cooperativa, 22: 1-45.

VARGAS VASSEROT, Carlos, 2012: "Sociedades Agrarias de Transformación. Empresas agroalimentarias entre la economía social y la del mercado». Editorial Dykinson. Madrid.

VARGAS VASSEROT, Carlos, GADEA SOLER, Enrique y SACRISTÁN BERGIA, Fernando, 2015: "Derecho de las sociedades cooperativas». Editorial La Ley. Madrid.

VICENT CHULIÁ, Francisco, 1998: «Mercado, principios cooperativos y reforma de la legislación cooperativa (estudio introductorio y de síntesis)», CIRIECEspaña, Revista de Economía Pública, Social y Cooperativa, 29:7-33.

WILLIAMSOM, Lionel. 1987: "The farmer's cooperative yardstick: cooperative refunds, patronage and revolving». AEC-54. University of Kentucky.

ZUBIAURRE ARTOLA, Miguel Ángel y ANDICOECHEA ARONDO, Lorea, 2010: «Fondos propios de cooperativas: aspectos en debate». Comunicación presentada al XIV Encuentro de AECA en Coimbra, Portugal.

ZUBIAURRE ARTOLA, Miguel Ángel, ANDICOECHEA ARONDO, Lorea y SAITUA IRÍBAR, Ainhoa, 2015: "Aplicación de la Orden EHA/3360/2010 sobre aspectos contables de las sociedades cooperativas: efectos en los fondos propios de las cooperativas de la comunidad autónoma del País Vasco». REVESCO. Revista de Estudios Cooperativos, segundo cuatrimestre, 118: 180-201. 


\section{Derechos de autor}

El Boletín de la Asociación Internacional de Derecho Cooperativo es una revista de acceso abierto lo que significa que es de libre acceso en su integridad inmediatamente después de la publicación de cada número. Se permite su lectura, la búsqueda, descarga, distribución y reutilización legal en cualquier tipo de soporte sólo para fines no comerciales y según lo previsto por la ley; sin la previa autorización de la Editorial (Universidad de Deusto) o el autor, siempre que la obra original sea debidamente citada (número, año, páginas y DOI si procede) y cualquier cambio en el original esté claramente indicado.

\section{Copyright}

The International Association of Cooperative Law Journal is an Open Access journal which means that it is free for full and immediate access, reading, search, download, distribution, and lawful reuse in any medium only for non-commercial purposes, without prior permission from the Publisher or the author; provided the original work is properly cited and any changes to the original are clearly indicated. 